\title{
Enhancing Team-Work and Supportive Working Environment of the Admission and Transfer Processes in Rural Mental Healthcare Services Using Lean Philosophy
}

\author{
Brian Mayahle ${ }^{1, ~ *}$, Stephen Parnell ${ }^{2}$, Rob Rolls ${ }^{3}$, Anthony Welch ${ }^{4}$, Jennifer Barr ${ }^{4}$, \\ Fumiso Muyambo 5 \\ ${ }^{1}$ Rural and Indigenous Mental Health Services, Central Queensland Hospital and Health Services, Queensland, Australia \\ ${ }^{2}$ Central Queensland Hospital and Health Services, Queensland, Australia \\ ${ }^{3}$ Central Queensland University, Mental Health Discipline Head, Queensland, Australia \\ ${ }^{4}$ Central Queensland University, Deputy Dean of Research, Queensland, Australia \\ ${ }^{5}$ Disaster Management Training and Education Centre (Dimtec), University of the Free State, Bloemfontein, South Africa
}

\section{Email address:}

Brian.Mayahle@health.qld.gov.au (B. Mayahle), Stephen.parnell@wales.nhs.uk (S. Parnell), rob.rolls@health.qld.gov.au (R. Rolls), a.welch@cqu.edu.au (A. Welch), j.barr@cqu.edu.au (J. Barr), fummmie@gmail.com (F. Muyambo)

${ }^{*}$ Corresponding author

\section{To cite this article:}

Brian Mayahle, Stephen Parnell, Rob Rolls, Anthony Welch, Jennifer Barr, Fumiso Muyambo. Enhancing Team-Work and Supportive Working Environment of the Admission and Transfer Processes in Rural Mental Healthcare Services Using Lean Philosophy. Journal of Public Policy and Administration. Vol. 3, No. 3, 2019, pp. 61-75. doi: 10.11648/j.jppa.20190303.11

Received: March 18, 2019; Accepted: May 8, 2019; Published: October 20, 2019

\begin{abstract}
Aim: To improve team work through joint development of clinical processes between regional, rural community mental health teams and rural hospitals using Lean philosophy. Background: There was lack of clarity of the roles and responsibilities of staff in the admission of mental health consumers in rural hospitals and in their transfer to regional acute mental health inpatient unit. This resulted in cross departmental animosity in Central Queensland health services which further led to compromised provision of consumer care. The impetus of this paper; therefore, is to present the application of Lean to the admission process in rural mental healthcare services as well as transfer to the regional acute inpatient unit in order to enhance teamwork and supportive working environment to improve consumer outcomes. Methods: The study utilized a qualitative approach where an online survey monkey was used to capture an in-depth understanding of the perceptions and experiences of the hospital and mental health staff pre- and post-implementation of the new processes. Key results: The participants reported improved collaborative working among the staff which resulted in more effective care provision for mental health consumers. Conclusion: Lean philosophy was successfully applied in creating effective administrative and clinical processes in rural and remote mental health services. Joint development of procedures and processes enhanced adherence to standards, improved teamwork and, consequently, ameliorated consumer outcomes.
\end{abstract}

Keywords: Lean, Hospital Admissions, Teamwork, Service Capability Framework, Patient Transfer

\section{Introduction}

There are no national or state-wide initiatives that have been developed and systematically implemented to comprehensively address issues of access, appropriateness of care and accountability in rural hospitals for mental health consumers [1]. The approach to provide such care has generally been ad hoc, driven by the need for urgent political solutions to local crises. The lack of clarity of the roles and responsibility of staff in the admission of mental health consumers in rural hospitals and their transfer to regional acute mental health inpatient unit resulted in cross departmental animosity in Central Queensland health services. These two processes were compromised by challenges such as 
service capability framework of the facilities, lack of clear processes on managing consumers who required admission or transfer, staff negative attitudes towards mental health consumers and lack of structured support from specialist mental health services.

Transfer of mental health consumers from Central Queensland rural and remote areas to the regional acute mental health inpatient unit was challenging. Coordination of transfer was reported to be poor due to unclear processes and designation of responsibilities, resulting in unnecessary delays of transferring consumers who would have been accepted for admission. The delays result in the consumer dissatisfaction and staff frustration. Moreover, Queensland government incurred huge transfer costs due to the geographical distances between the rural areas and the regional center, Rockhampton. Sustainable solutions to meet the challenges of mental health admissions and transfers, as well as increasing capacity, require adequate analysis of the processes. Identification of clinical process steps from admission to discharge from the facility, either to an inpatient acute mental health facility or back to the community, was necessary before any solutions could be implemented.

Lean thinking has shown great potential for improving quality of care and processes in several departments of the general healthcare system [2-4] Much success in the healthcare industry has been reported in emergency departments, pharmacy, radiology, pathology, transport, operating theatres, human resources, information technology or food services; to generate a continuous improvement culture through identification and elimination of waste within the processes [5]. Lean is described as a process management philosophy that examines organizational processes from a customer perspective with the goal of limiting the use of resources to those processes that create value for the end customer [4].

The impetus of this project; therefore, was to develop clear processes on managing rural hospital mental health admission and transfer processes to the regional acute inpatient unit in cahoots with all key stakeholders. Lean principles were used to ensure improvement of the work environment and teamwork, hence contributing to more effective care of consumers.

\section{Research Methodology}

The study utilised qualitative methodology. It implemented naturalistic inquiry as proposed by Braun and Clarke [6]. The socio-technical aspects of Lean (humanistic factors) could be better understood by having a good understanding of staff perceptions of internal quality and Lean implementation in healthcare. The healthcare industry has various cultures, structures, professional bureaucracies and norms which require qualitative methods to explore people's perceptions and experiences [7-9].

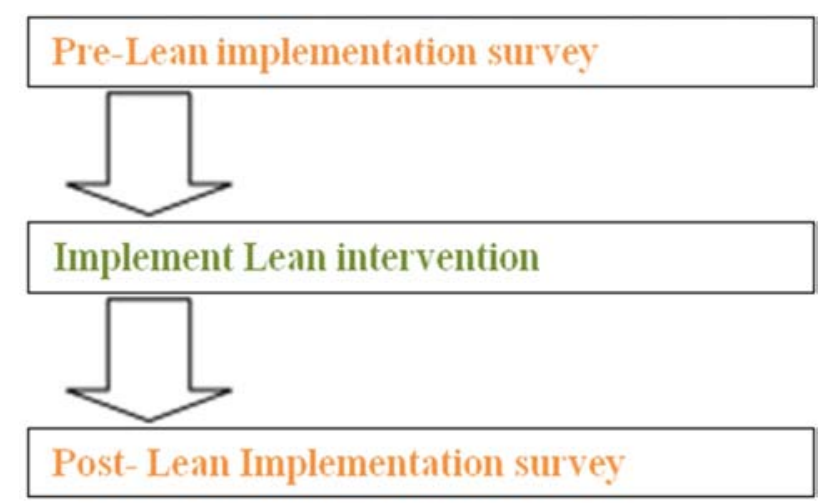

Figure 1. The Research process.

\subsection{Purpose of the Pre and Post-Lean Implementation Questionnaires}

The online survey monkey questionnaires had open ended questions to allow participants to express their pre- and post-Lean implementation knowledge, views, experiences and perceptions regarding the quality improvement methodology. The post-Lean implementation questionnaire was addressed to staff who participated in the Kaizen workshops (group activity which can last up to five days, in which a team identifies and implements a significant improvement in a process). The questionnaires are attached as Appendices A and B respectively.

\subsection{Sampling}

This study used convenience sampling. A convenience sampling framework was appropriate because a specific health region was targeted to consider the usefulness of this business approach.

\subsection{Administering the Online Survey Monkey}

The online survey monkey questionnaire was created and administrated by an independent administrator with a locked password. It had a consent box and an additional information sheet contained a statement that there were no consequences if they decided not to participate. Participation was not mandatory but was highly recommended to improve the services.

\subsection{Ethics Approval}

This project required ethics approval as it involved human participants. Ethics approval was sought from the appropriate institutional ethics committees, Central Queensland University (CQU) and Central Queensland Health and Hospital Services (HHS) Human Research Ethics.

\subsection{Anonymity Confidentiality}

The online questionnaire was anonymous; therefore, participation or non-participation in the study was non-identifiable. It was locked with a password and administered by an independent administrator. 


\subsection{Qualitative Data Analysis}

A total of 26 responses were elicited from 40 participants, which translates to $65 \%$ response rate. The participants comprised of rural mental health staff, the acute care team and the rural hospital staff. The responses could not be categorized to the specific areas because of the need to maintain anonymity. Nevertheless, the cohort of participants was a cross-section representation of the regional mental health and hospital workforce staffing profile which includes psychiatrists, allied health, nurses and administration staff.

The responses to the open-ended questions used in the online questionnaire were analyzed following the six phases of thematic analysis as described by Braun and Clarke [6] who posit that it is a method for identifying, analyzing and reporting patterns (themes) within data. This method was chosen because it organizes and describes the data set in (rich) detail while providing in-depth interpretations of the data in meaningful ways [10]. Therefore, in line with the six phases by Braun and Clarke [6] we familiarized ourselves with the data by independently reading through the responses so as to come up with a well-organized story. Secondly, we generated initial codes, which resulted in 7 identified codes. The third phase was to search for themes. 7 codes yielded 4 clusters which were reviewed to generate initial themes. In the fourth phase we reviewed the initial themes by cross-referencing them. All participants were identified and given equal weighting. The emergent themes were synthesized and the process was repeated until there was minimal overlap in the remaining categories. Fifthly, we defined and named themes after there was minimal overlap; and five themes emerged. Finally, we produced a report. The significant statements, initial codes, clusters and themes are presented in Appendix C.

\section{Presentation of Pre-Lean Findings}

\subsection{Tension in Maintaining Supportive Teams}

The theme that emerged from the survey was tension in maintaining good and supportive teams.

\subsection{Clusters Under the Identified Theme}

The identified clusters which fall under this theme are silo working; lack of respect, multi-disciplinary functioning, and relevant education and training.

\subsubsection{Silo Working}

Silo working was reported to be caused by inherent departmental structures and well embedded behaviors, values and norms and resulted in interdepartmental animosity. The teamwork challenges were also reported to exist at different levels; within mental health teams, regional versus rural versus inpatient and mental health versus general health. The following statement expressed one of the participants' views; "Something must be done about relationships between different teams, mental health teams and hospitals; Rockhampton mental health and outlaying community."
Another participant indicated the lack of communication between the teams as a cause of cross-departmental animosity by stating that; "Increase communication between rural and non-rural areas."

Teams working in silo and the tensions among them were also attributed to a lack of common understanding of departmental service capability frameworks, compounded by unclear processes and pathways. Moreover, it was highlighted that there had been no real resolutions put in place despite ongoing misunderstandings among staff in different departments, which impacted on clinical decisions. Participants expressed this opinion through various statements such as; "Hospital staff have their own understanding of what their service capability framework allows what they can do and mental health have their own understanding of the same, resulting in strained relationships, which subsequently affects decision making processes and patient outcomes". Another one stated that "there is no true clarity of discussions or processes being developed after consultation with general staff; as a result, it becomes very difficult to negotiate some treatment plans with the staff in the general hospitals when you require overnight admissions in rural hospitals or need their assistance to transfer a patient to the main hub services". These two examples highlight the level of dysfunction between departments resulting in sub-optimal operations and consumer outcomes.

\subsubsection{Lack of Respect}

Some participants expressed that the lack of respect resulted in some clinical decisions being made based on the interdepartmental animosity rather than on the best interest of the consumer, as shown in the following statements: "It becomes very difficult to negotiate some treatment plans with the staff in the general hospitals when you require overnight admissions in rural hospitals or need their assistance to transfer a patient to the main hub services". Another participant mentioned that "Rockhampton region is the priority and the rest of the Central Queensland Mental Health Service is secondary, which results in lack of respect between staff in different settings". To the challenge of lack of respect another participant added the lack of involvement in process and key quality improvement processes. The participant stated that "any key improvements will involve the regional staff and we are not involved, only for procedures to be cascaded to us for implementation".

\subsubsection{Lack of Multidisciplinary Working}

Another cluster which was identified to underpin the theme of tensions in teams was lack of effective multidisciplinary working. One participant also mentioned that "some clinicians do not respect multidisciplinary working so professional's turfs are still very much in play". The participant further mentioned that the lack of respect among medical, allied health and nursing staff further erodes team working.

\subsubsection{Relevant Education}

Lack of relevant education to improve staff knowledge 
was also identified as contributing to tensions in supportive teams. One participant mentioned that "lack of specific training in mental health for regional and rural emergency department and ward staff results in the staff working in silos and being resistive to accept and support mental health consumers". Other participants validated the need for relevant training to staff by suggesting having joint training with CQU and Queensland Centre for Mental Health Learning to up skill the rural and regional emergency department (ED) and general hospital staff.

\section{Lean Implementation (Research Intervention)}

A three-day kaizen workshop to create the current state of the admission and transfer processes was conducted by key representatives from rural community mental health staff, rural hospital emergency department, and regional acute care team. Several issues were raised and the majority was the same as the pre-Lean issues. The kaizen team indicated that interdepartmental staff animosity was causing silo working. The group further elaborated that mental health staff were of the opinion that rural hospitals ED staff have their own understanding of the service capability framework and this is often misinterpreted, resulting in rigid adherence to the established roles and poor integration of healthcare provision. Such a situation was further exacerbated by no clear joint departmental guidelines as recommended by the Queensland state-wide policies. Interdepartmental silo working results in compromised consumer safety and unnecessary additional costs related to inappropriate transfers of consumers from rural hospitals to the regional mental health inpatient unit.

Another significant issue raised in this workshop was lack of flow in the process. Flow is described as linking the, otherwise, disjointed links to ensure that consumers move in the process without any delays or waits. Issues on flow of information in the system were found to impact on treatment delays and clinicians' involvement in provision of care. Any interruption results in disruptions to flow. The major obstacles to flow are the seven wastes as described by Taiichi Ohno [11]. Black and Miller [12] give seven types of flow in healthcare. However, the three major types of flow which were distinctive and relevant to this admission process were:

1. Consumer flow.

2. Information flow.

3. Clinicians flow.

Another identified challenge raised in this workshop was the unclear processes and procedures that resulted in significant variation in the way clinicians managed consumers admitted in rural hospitals. A lack of clarity in clinical processes and roles regularly led to confusion as to who should be responsible for the provision of care. This lack of clarity in clinical processes led to common complaints from service users, other health service providers and rural and regional Queensland health staff. The kaizen team also acknowledged that Central Queensland region is sparsely populated, compounded by a tyranny of distance between geographical areas. The huge distances resulted in fragmented service provision, inaccessibility and inefficiencies. As a result, a more robust management of the mental health consumers in their localities was required. After reaching the consensus that real problems existed in the current process, the team developed the current state process map of the admission process and then brainstormed to identify new ideas to improve flow. To improve flow and to create the desired future state the team used the acronym FECRS which stands for:

F- Fix broken operations

E- Eliminate waste

C- Combine or collocate operations

R- Rearrange operations

S- Standardize and simplify operations

Once the future state processes were developed, the team then drafted the desired future state flowcharts and rural mental health admission care plan. The second and third day of the kaizen workshop focused on improving the transfer process. The workshop participants included external partners to the Queensland mental health services such as Queensland Ambulance Services (QAS) and Queensland Police Services (QPS). The issues that were identified to be associated with the transfer process immensely impacted negatively on the consumer's journey. Every mental health transfer from rural areas to the regional acute mental health inpatient unit required diligent, effective coordination because there were several internal and external departments involved in the transfer. The decision-making process to transfer the consumers was flawed by conflicting priorities in the system. The flaws in the system had previously been reported to senior leadership without any real sustainable solutions being developed. The utilization of a single loop approach to solve the problems resulted in frustration among staff. This workshop facilitated a different systematic problem-solving approach to address the issues and develop long term countermeasures. The issues included:

1. Risk assessment of consumers before transporting for transfer.

2. Cost of transfer.

3. Delays to arrange transfers.

4. Decision making process to transfer.

\subsection{Workshop Objectives}

The main purpose of the workshop was to collectively find resolutions to the issues pertinent to mental health transfers. The workshop was also targeted to:

1. reduce the lead time from when a decision to transfer a consumer is agreed upon to the point when the consumer is admitted in Rockhampton mental health inpatient unit;

2. minimise unnecessary transfers from rural hospitals to Rockhampton mental health inpatient unit;

3. eliminate unnecessary waste in each process step;

4. improve the consumers' journey during the transfer process; there is evidence in literature that consumers' ongoing engagement with the mental health services depends 
on their experience when they first entered the services;

5. minimise disruptions at partner services;

6. reduce delays in transferring consumers;

7. reduce waiting time for the consumers;

8. reduce interdepartmental animosity and improve morale of staff;

9. establish clear responsibility and accountability for coordinating transfers;

10. improve consumer safety; and

11. develop a good understanding of the current transfer policy.

However, the workshop excluded formulating:
1. new policy,

2. principles that would guide a transfer, or

3. diagnostic conditions which would result in the transfer of a consumer.

\subsection{Mapping the Current Transfer of Mental Health Consumers Process}

The team mapped out the current transfer of mental health consumers process and identified issues that occurred at each process step or task. The team used sticky notes to map out the processes as shown in Figures 2 and 3.

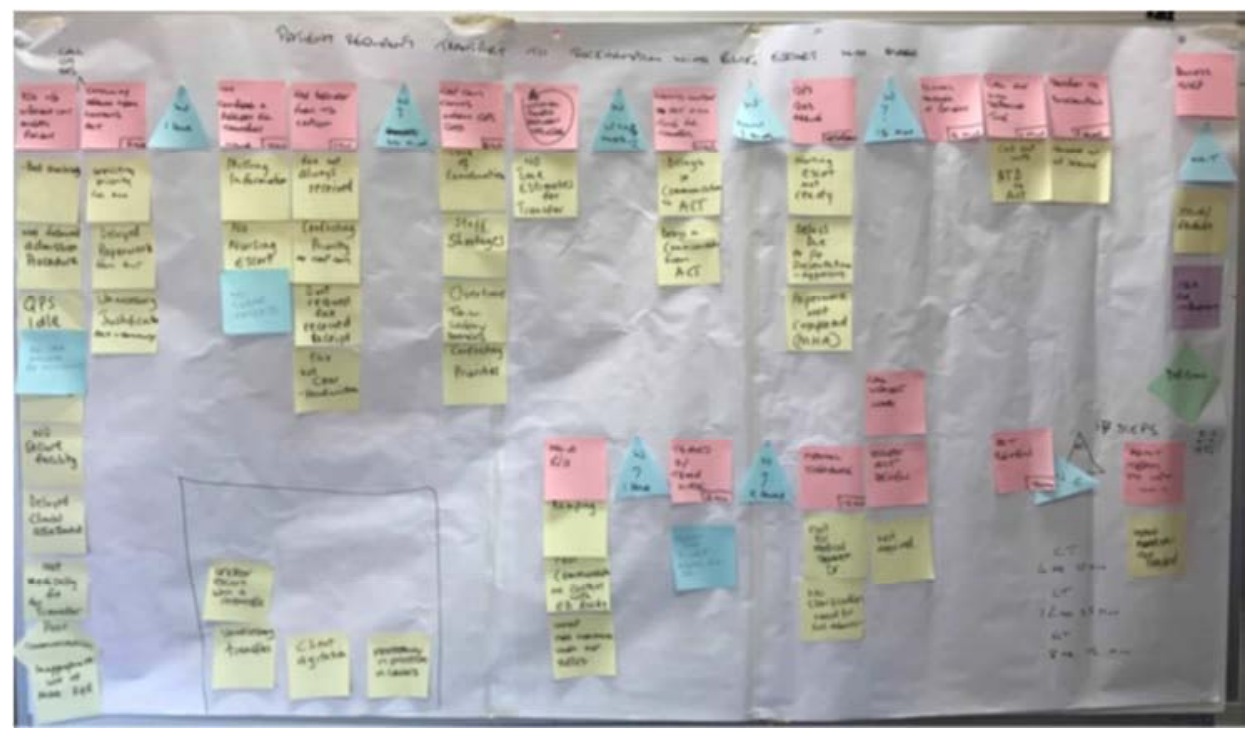

Figure 2. Consumer transfer current process map with sticky notes.

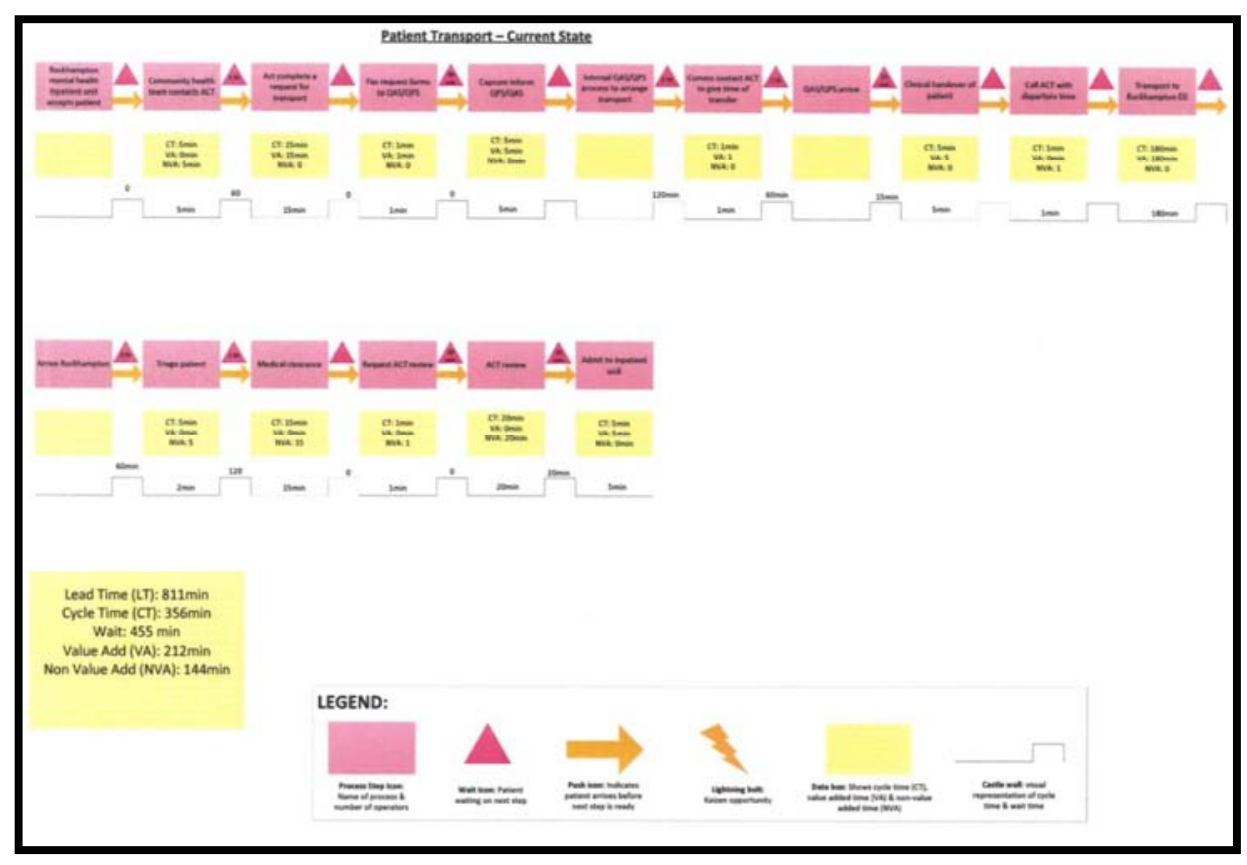

Figure 3. Patient transfer current state map.

The team was allowed sufficient time to discuss the issues openly without antagonizing each other. After mapping out the current state of the transfer process the team was asked to generate improvement ideas. The team members were asked to perform this exercise individually, in silence, and several ideas were generated (Figure 4). 


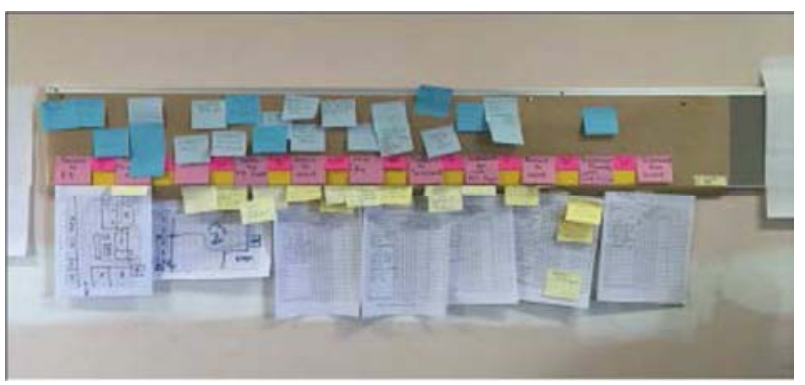

Figure 4. Idea generation exercise pictures.

\subsection{Themes that Evolved from the Generated Ideas}

1. Reduce excessive medical clearances; if a consumer has a medical clearance at a local rural facility and does not have sedation en-route to the regional centre they should not have another medical clearance prior to the actual admission

2. Develop clear process and standard work instructions

3. Clarify whose responsibility it was to provide nursing escort for mental health consumers in rural areas

4. Reduce clinical hand-offs by allowing local teams to directly request QAS and QPS rather than Acute Care Team

The team then started to map out the desired future state of the transfer process incorporating the ideas they had generated the previous day. To achieve that team focused on how they would improve flow of:

1. Information

2. Consumer

3. Clinicians

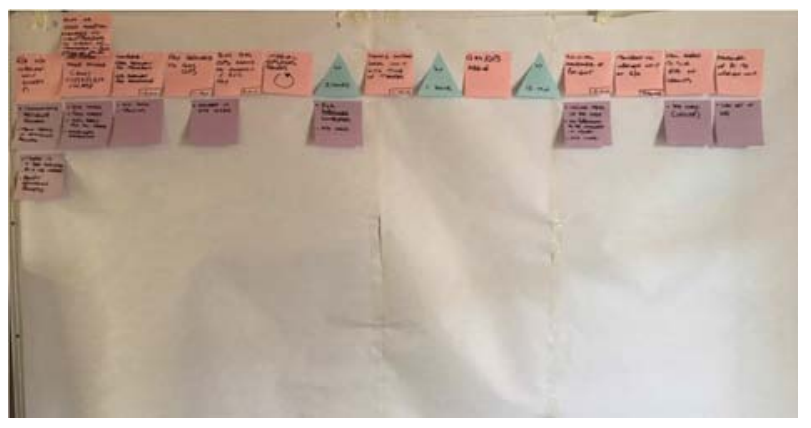

Figure 5. Consumer transfer future state process map.

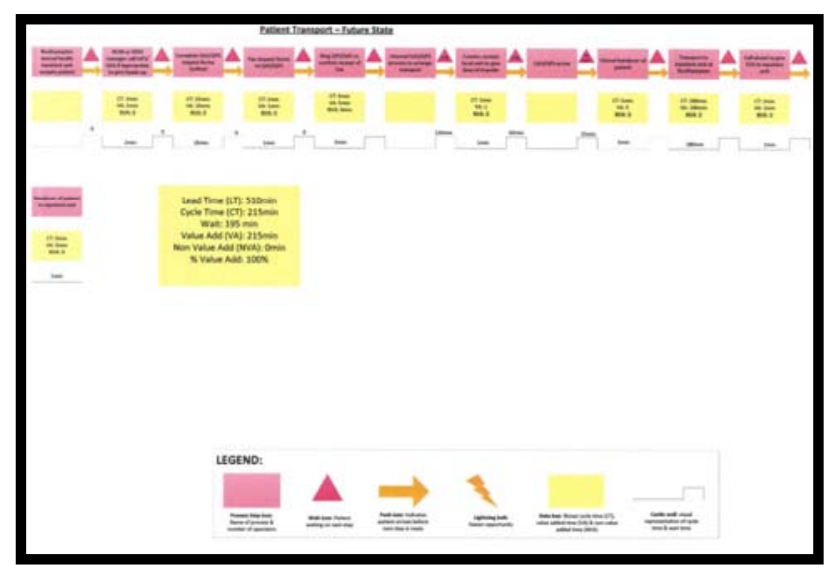

Figure 6. Future state map for consumer transfer coordination.
The future state map for coordinating mental health consumer transfers had several notable efficiencies, as shown in Table 1, which include:

1. Reduced total lead time.

2. Reduced waiting times.

3. Reduced process steps, and.

4. Reduced non-value added time.

Table 1. Comparison of current and future state efficiencies.

\begin{tabular}{lll}
\hline & Current state & Future state \\
\hline Lead time & 811 minutes & 510 minutes \\
Waiting time & 455 minutes & 195 minutes \\
Number of process steps & 17 & 12 \\
Non value-added time & 144 minutes & 0 minutes \\
\hline
\end{tabular}

The lead time was decreased by reducing waiting time, unnecessary process steps and improved cross departmental collaborative working relationships. The reduction in waiting time for decisions resulted in improved efficiency. The non-value-added time was reduced by $100 \%$. Most of the non-value-added time emanated from waiting for a decision from other teams who would have other conflicting priorities. The reduction in the numbers of the process steps or tasks led to the reduction in the number of clinical handoffs. Reduction of clinical hand-offs is synonymous with improvement of consumer safety through reduction of potential errors from miscommunication. Most of the process steps that were removed from the current state map were tasks that used to be performed by the Acute Care Team. Such reduction not only expedited the process, but also reduced the workload of Acute Care Team clinicians who have recently been complaining of excessive workload due to many tasks being allocated to them whenever district improvement activities occurred.

\subsection{Consultation with All Stakeholders}

Standard work is not a management tool to be imposed coercively on employees. Moreover, it is not trying to enforce rigid standards that make the jobs routine and degrading, but it is the basis of employee empowerment and innovation in the workplace. Therefore, the draft flowcharts were emailed to various groups, including clinical director of mental health, rural hospitals director of medical services, and directors of nursing of rural hospitals who further consulted with their colleagues. The consultation occurred for a month to allow all key stakeholders to provide some input.

\subsection{Key Results from the Workshop and Follow-up Consultations}

Taiichi Ohno [11] states that standard work is the basis of having stabilized processes before any continuous improvement. It is impossible to improve any process until it is standardized (No kaizen without standard work). If the process shifts without a set standard then it will be viewed as another variation. The key results from the workshops were standard flowcharts and the admission care plan which would 
address the issues which were raised in the workshop and also in the pre-Lean surveys. Figure 7 shows the voluntary admission of mental health consumers in rural hospitals. The figure clearly shows the step-by-step tasks to be followed when a consumer is to be voluntarily admitted in a rural hospital.

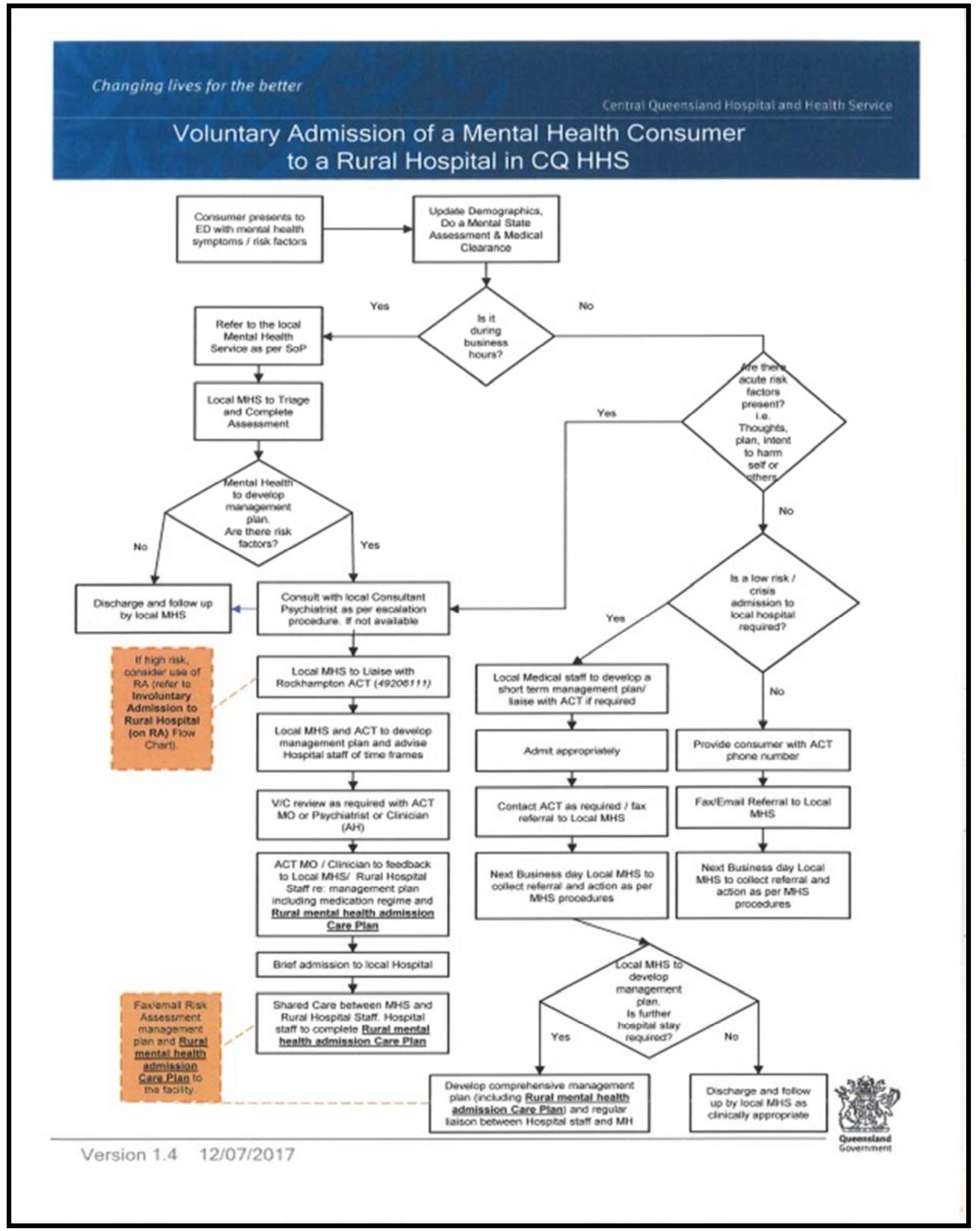

Figure 7. Voluntary admission of a mental health consumer to a rural hospital.

Figure 8 is a step-by-step flowchart which guides staff on how to respond to a consumer who presents to a rural hospital on an emergency examination order under the public act. 


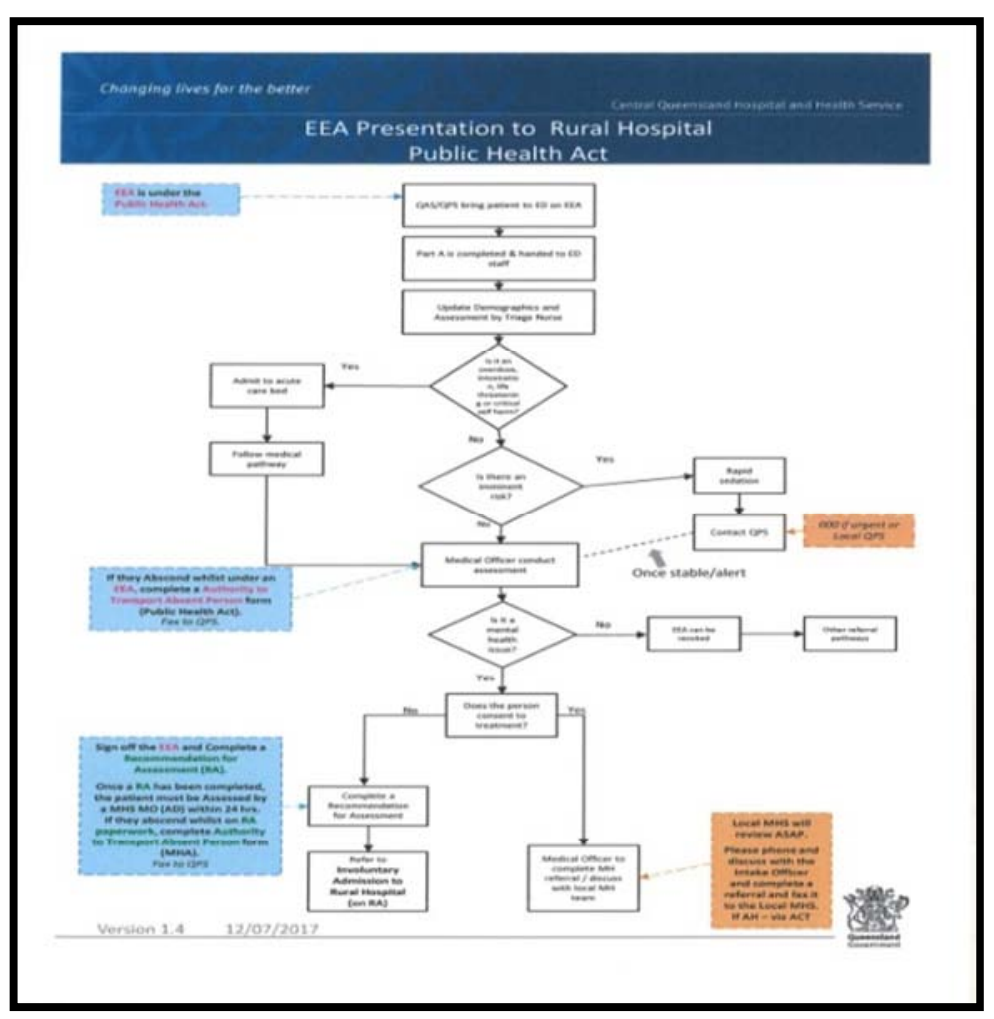

Figure 8. EEA presentation to rural hospital under public health act.

Figure 9 highlights simple step by step flowchart for managing an involuntary mental health consumer at a rural hospital when there is bed block at the regional acute mental health inpatient unit.

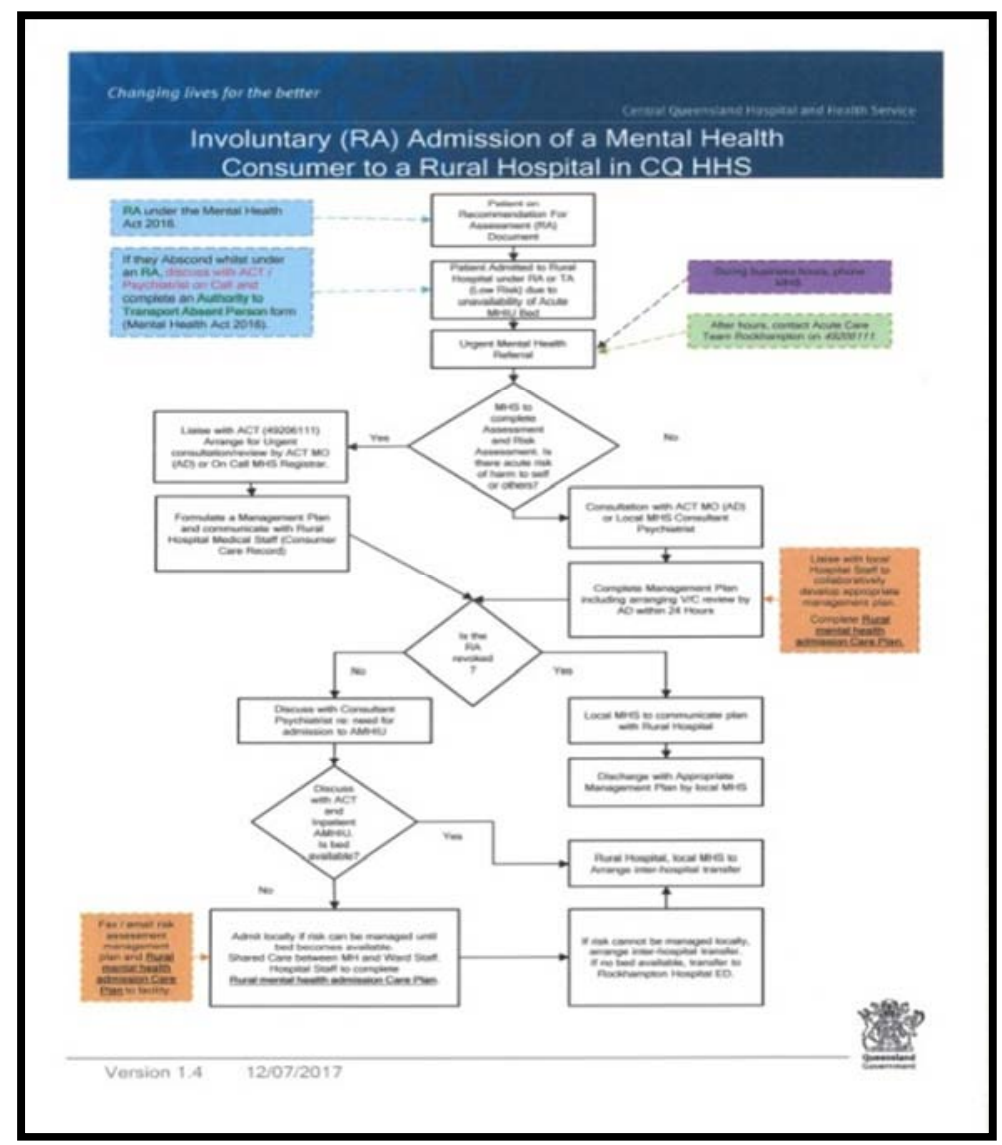

Figure 9. Involuntary (RA) Admission of a mental health consumer to rural hospitals. 
The team developed rural mental health consumer admission care plan as shown in Figure 10. The rural mental health admission care plan would be completed by mental health teams and faxed to the rural facilities if the admission was done after hours. The community mental health teams would complete the care plan and share with the local hospital staff if the admission was done during working hours. The care plan would indicate the expectations of care for the consumer while admitted at the facility.

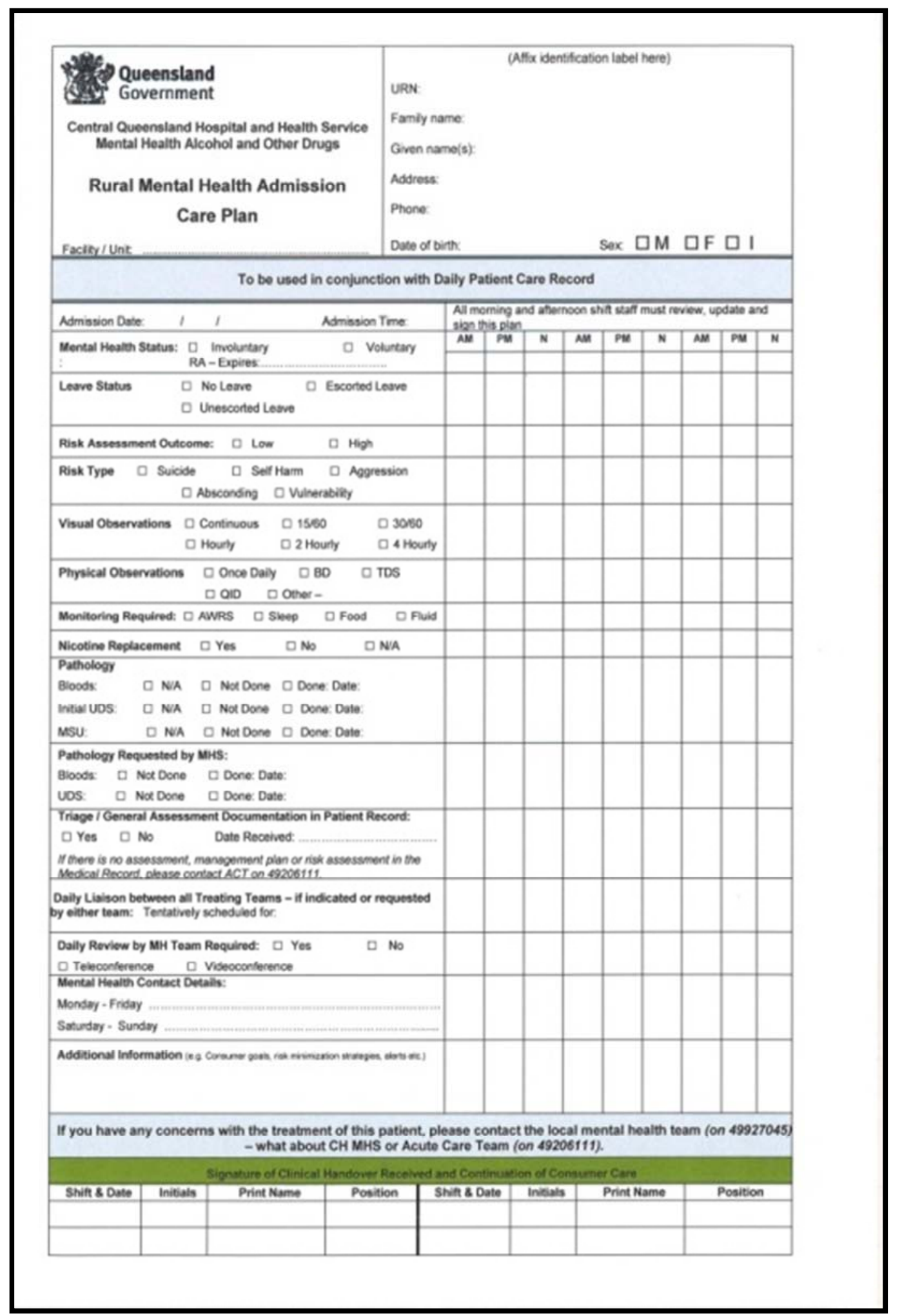

Figure 10. Rural mental health consumer care plan. 

Processes in Rural Mental Healthcare Services Using Lean Philosophy

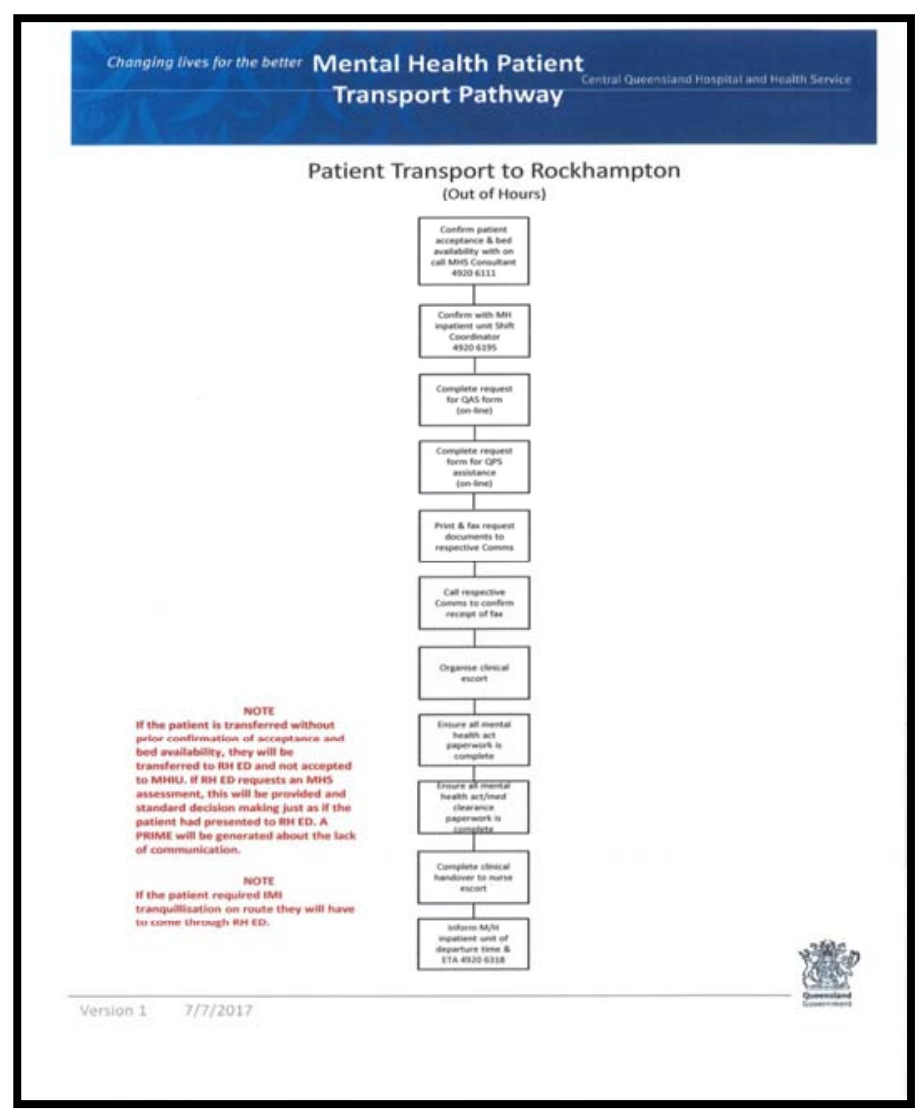

Figure 11. Flow chart - consumer transport coordination (working hours)

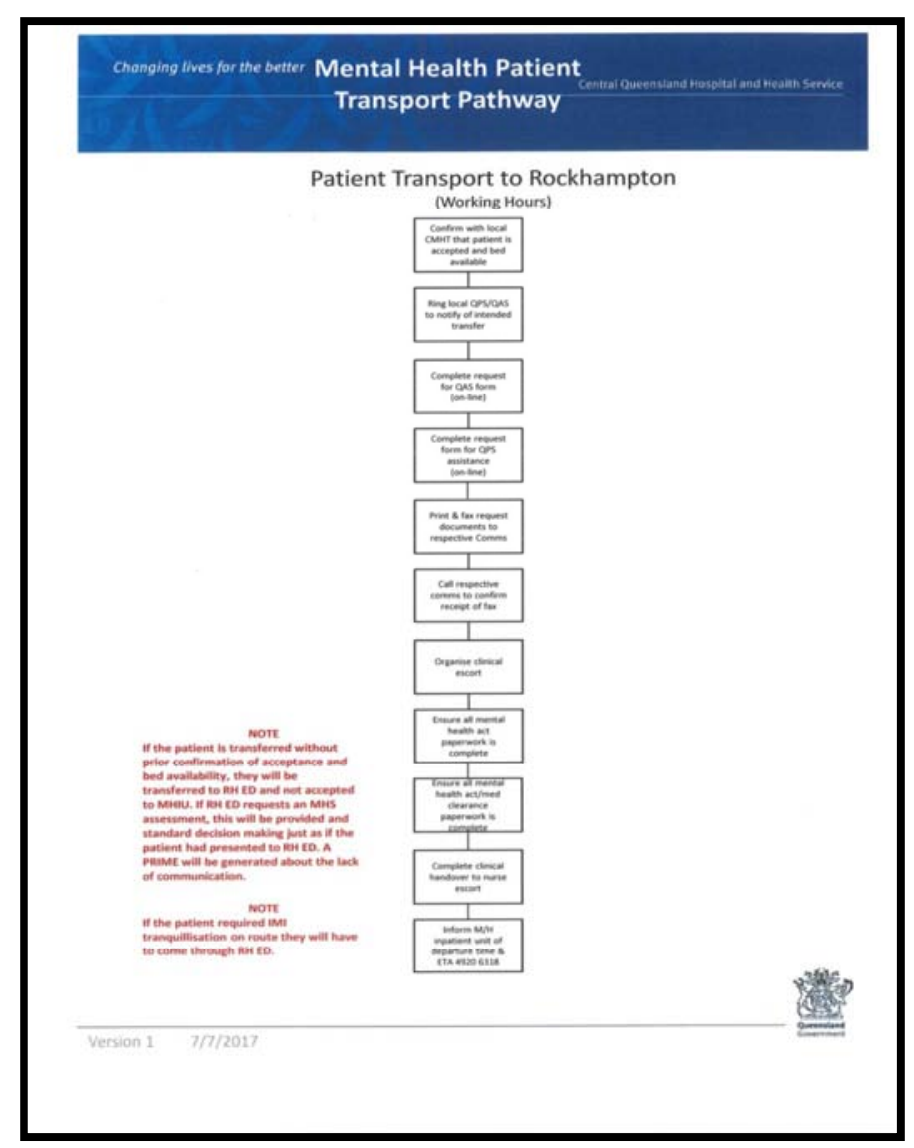

Figure 12. Flowchart - consumer transport coordination (out of hours). 


\subsection{Communication Plan}

The team developed a communication plan and standard work training implementation spread sheet for systematic dissemination of the newly created standard work instructions and flow charts. The communication plan identified all the stakeholders, a timetable and how progress was evaluated.

\subsection{Rolling Out the Standard Work Instructions}

The standard work instructions were rolled out to community rural mental health staff, rural hospital staff, other remote and multipurpose facilities in the district and the acute care team staff. Clear roles and responsibilities were established. The district medical officers were allocated the role to inform all the medical officers about the newly developed flow charts and care plans. Nurse educators and community mental health seniors were allocated a role to inform the nursing staff in the rural hospitals. The clinical director was allocated a role of informing all the psychiatrists at the regional mental health services. Paper folders were developed by the administration officer for all the facilities and located in rural hospitals in easily accessible areas within the hospital. Copies of all the documents in the paper folder were also placed in an electronic folder as desktop folders in all rural facilities. Afterwards, an email was sent out to all staff to inform them of the locations of the documents. In addition, the rural mental health team manager visited all rural facilities to discuss the new processes, flowcharts and standard work instructions.

\section{Post-Lean Intervention Findings}

The post-Lean qualitative data analysis followed the Braun and Clarke [6] process of thematic analysis. As with the pre-Lean survey, the post-Lean survey monkey questionnaire was sent out by the independent administrator on 30th November 2016, specifically to staff who participated in the workshops and those who directly utilized the developed processes. The themes from the post-Lean finding are discussed and supported by direct quotes from the participants' responses. The themes that emerged and were relevant to this study are shown in Appendix D

\subsection{Effective Collaborative Working Between Departments}

One of the central themes that emerged from the post-Lean qualitative questionnaire data was effective collaborative working between departments to improve processes, relationship building and consumer outcomes, as shown in Appendix D.

\subsection{Clusters Under the Identified Theme}

The identified clusters that fell under this theme were networking and building relationships, involvement of staff from different departments, collaboration between departments and empowerment of staff.

\subsubsection{Networking and Building Relationships}

Lean implementation enhanced networking and building relationships by providing an opportunity for reflection and review processes with colleagues. Two participants expressed this view by stating that Lean "provided a good opportunity to sit down with colleagues and look at current processes and working towards improvement" The other one said that "the workshops enabled good reflection on the way we work, find efficiencies together and was also good networking, relationship building, and personal development/reflection opportunities". In addition to network building, another participant noted the aspect of improved teamwork by stating that Lean "has helped us to work as a team". Furthermore, another participant indicated that improved teamwork consequently led to staff taking ownership of the process, as shown in the following statement: "With more consistent processes implemented and having had the team decisions where everyone takes ownership, if there has been a problem, staff are able to discuss as a team and come up with solutions that are sustainable and separate the processes that's not needed".

\subsubsection{Staff Involvement in Developing Processes}

Active involvement of staff from different departments improved as a result of Lean implementation. One of the participants expressed this view by stating that "the workshops have been of great benefit in getting all parties involved in care provision to get together, fine tune processes and implement them together". Two other participants highlighted the same point by stating that "I was skeptical at first; however, Lean enabled good discussions which encouraged different clinicians to be involved". The other one stated that "initial discussions were held to identify problems, and activities were carried out to develop new standard practices by all the staff". Moreover, participant involvement in developing the processes resulted in enhanced knowledge of cooperate requirements.

\subsubsection{Enhancing Corporate Knowledge}

Lean implementation enhanced staff understanding of corporate knowledge which improved collaborative working. Two participants expressed this point of view through the following statements: "Kaizen Workshop gave an insight into other service areas demand and issues". Another participant noted that, "coming from different clinical practice, I was able to quickly grasp the processes". However, another participant further highlighted that involvement in the workshops assisted in developing an understanding of the constraints within the services. The participant stated that Lean "enabled me to fully understand the rural mental health pathways and the issues encountered by staff and patients on daily basis". The enhanced knowledge about the constraints contributed to the overall understanding of the cooperate knowledge which resulted in the effective collaboration between the departments. 


\subsubsection{Effective Collaboration}

Lean initiatives heightened effective collaboration which resulted in improved teamwork and consequently improved consumer experiences. One participant expressed this view by stating that "Lean has helped collaboration between external and internal stakeholders to improve patient experiences". This view was reiterated by another participant who stated that "Lean initiatives have made work to be more time efficient and collaborative". Lean initiatives contributed to empowerment of staff which enhanced staff satisfaction through visible participation and sharing of ideas. One participant expressed this view by stating that, "I do look forward to using the Lean process more in further change and activities in this workplace. I found even from the one workshop it was empowering and increasing work satisfaction". Two other participants mentioned the same point by stating the following: "Lean initiatives have provided a way to have visible participation and sharing ideas to include staff in the decision-making process" and "The rural mental health team have made suggestions to improve their workplace and have made a number of significant improvements for our consumers".

\subsubsection{Increased Accountability}

The second theme derived from the post-Lean qualitative surveys was increased accountability for clinicians to improve the quality of care provided. The two identified clusters that support this theme were clear expectations and responsibilities as well as improved accountability for staff.

\subsubsection{Clear Expectations and Responsibilities}

Enhanced clarity of expectations and responsibilities for staff resulted in providing consistent care to admitted consumers in rural hospitals. One participant indicated that "developing standard work and clear processes through Kaizen workshops gave clarity on expectations and resulted in consistency". Another participant stated that "clinicians now have a better understanding of their responsibilities".

\subsubsection{Improved Accountability for Staff}

Improved accountability of staff ensured that tasks are completed timely. Three participants expressed this view by stating that "all clinicians are now accountable for the work they do or not have done. It also reminds clinicians of work they have not yet completed and are able to track their cases". The second one noted that "It makes clinicians to be more accountable". The third one stated "The positive outcome of introducing the Lean initiatives is it has made clinicians to be more accountable, streamline processes and to give a structure/framework to the work we do in mental health" Another participant also mentioned that Lean initiatives resulted in increased staff accountability as well as improved teamwork. According to this participant, "the implementation of the rural mental health care plan and transfer process makes clinicians more accountable and ensures that staff get on top of their care expectations. It also promotes team work as colleagues check on each other and help each other to get on top of the expectations". The improved teamwork resulted from improved camaraderie among colleagues as Lean created opportunities for staff to help each other to achieve optimum care for consumers.

\section{Discussion}

Pre-Lean implementation surveys highlighted the tensions in maintaining supportive teams in regional and rural areas. Underpinning the pre-Lean theme were several other factors that included silo working, lack of respect, lack of multi-disciplinary working and lack of relevant education. However, post-Lean implementation survey was indicative of positive changes in work environment. These included effective collaborative working between departments; increased accountability for staff, and improved standardised processes that engendered changes in attitudes of staff towards Lean implementation in healthcare. The changes brought about by Lean made the services more efficient through reduction of waste and reduced variation, thus increasing consumer safety.

One of the key contributing factors to the improvements that were achieved was the involvement of the participants in setting up the initiatives and decision-making processes; hence, they viewed the processes as supportive mechanisms which enhanced collaborative working between departments and improved consumer safety. The participants felt empowered in the process; therefore, they viewed the flowcharts and rural admission care plan as contributing to better teamwork. This corroborates the view of Liker [3] in his principles 9 and 10 of the Toyota management systems: if people or teams are educated about the philosophy, empowered and involved in the decision-making process, they will live and breathe the philosophy, resulting in improved staff and customer satisfaction. The positive effects of Lean on healthcare workers through worker empowerment and control over working conditions increased opportunities to spend time on direct care and other more satisfying aspects of work. This confirms the view of Graban [13] that Lean is an approach that can support employees and physicians, eliminating roadblocks and allowing them to focus on providing care.

In addition to eliminating waste and creating efficiencies, the study shows that the Lean workshops facilitated a forum where the participants examined the way service provision was undertaken with other staff from different departments, which led to a better understanding of the constraints within the whole value stream. The participation in kaizen workshops increased interdisciplinary functioning and led to a reduction of silo working and departmental animosity through enhanced understanding and appreciation of the different priority issues and inherent systematic challenges in different departments.

It can be interpreted that the Lean workshops improved respect among the different teams as the staff changed their perceptions about the work conducted by each different department. The finding from this study validates Martin, Kolomitro, and Lam [14], who emphasised the benefits to organisations if employees work together towards a common organisational goal. Graban [13] concurred by stating that 
Lean helps break down barriers between disconnected departmental silos, allowing different hospital departments to better work together for the benefit of consumers. Furthermore, the involvement of staff from different departments, in the development of flowcharts and rural admission care plan increased adherence and compliance to procedures.

The unclear processes and lack of understanding of what was needed to manage mental health consumers in rural hospitals created disharmony among teams at the pre-Lean stage, as reported by study participants. When the processes were unclear, staff struggled to provide good quality of care and when clinicians started to struggle to provide the good quality care to consumers, they became frustrated, which consequently resulted in tensions among team members. The study revealed that the improved standard work process reduced variation, facilitated quick orientation to new staff and improved team work and accountability of staff. This substantiates the view of Black and Miller [12] that unnecessary variation due to unclear process can be addressed through development of standard work practices. Hummel [15] concurred by stating that standard work improves the socio-technical aspects of Lean, which includes teamwork.

The consumer transfer workshop attracted audiences from external partners, thus helping to disseminate the Lean philosophy both internally and externally. External organisations were very excited to be involved in improvement work within Queensland Health that gave them confidence that something was being done on an issue that has persistently resulted in interdepartmental or cross departmental misunderstandings. By and large, even though Lean techniques began as a way to improve manufacturing processes, lessons gained show that many of the most effective methods can be transferred to other industries, including healthcare. From the responses of the participants it shows that Lean contributed to the improvement of teamwork, camaraderie and collaborative working to develop a common understanding of problems to achieve better outcomes for the consumers.

\section{Conclusion and Implications}

Lean philosophy can improve healthcare clinical processes in regional, rural and remote hospitals. The key element to achieving required goals is to involve the clinical staff in identifying the problems that will subsequently result in relevant solutions to be developed and adhered to. When all stages of clinical service provision are clearly defined then services can be labelled in a proactive manner that is aligned with individual needs; therefore, leading to improved consumer outcomes. After clearly describing the care processes, a collaborative working approach among all stakeholders, including community mental health teams, is required to seamlessly navigate the consumers through the system. Liker [3] states that principle 11 of Toyota focuses on Lean organizations working close together with partnering organizations to improve service delivery to their common customers. The Queensland state-wide models of service encourage mental health staff and rural hospital staff to have joint procedures for managing mental health consumers who present to emergency departments. However, the nit grit details of how this can be achieved depends on the health and hospital services to ensure expeditious, safe, brief admissions of mental health consumers in rural facilities and also their transfer to the regional acute inpatient unit.

\section{Acknowledgements}

We are immensely grateful to all the Central Queensland rural mental health staff and rural hospitals staff, clinical director CQMHAODS and the acute care team for your valued contributions to the success this research work.

\section{Appendix}

\section{Appendix A: Pre-Lean Qualitative Questionnaire}

Please tick the box provided if you consent to participate in this research study

Writing in usual conversation style is acceptable to answer the questions in this document

Describe your understanding of lean thinking philosophy?

Describe your understanding of mental health patients' journey in central Queensland mental health services?

What do you consider as the "value adding" activities/steps in a patient's journey within the mental health service?

What do you believe are some of the "non- value added" activities/steps in the current clinical process?

Describe the key performance indicators which relate to patients' journey when they are referred to central Queensland mental health services?

What do you think are the challenges for meeting the current key performance indicators?

What are your suggestions in relation to IT, documentation, and data systems that will improve your workload and meeting key performance indicators?

Describe your understanding of the overall central Queensland mental health services strategy?

Describe the communication style between senior leadership and staff within the central Queensland mental health services?

What are your suggestions of how employees can be empowered and encouraged to be actively involved in improving the clinical processes and their work environment within central Queensland mental health services?

Based on your experience and knowledge, what are your suggestions about process improvements that are needed in Central Queensland mental health services to improve patient experiences?

Any other comments?

\section{Appendix B: Post-Lean Qualitative Questionnaire}

Please tick the box provided if you consent to participate in this research study. 
Writing in usual conversation style is acceptable to answer the questions in this document

1. What is your opinion of the CQWay/lean activities in which you have participated?

2. To what extent has your work with lean contributed to better workflow?

3. To what extent has the implementation of lean improved your work environment?

Which factors do you think obstructed the successful implementation of CQWay in rural mental health services?
4. Which aspects of Lean resulted in positive outcomes for, patients, you and the team?

5. Please describe how lean implementation in rural mental health services has helped you to perform your work?

6. Please describe how lean implementation has helped you to understand clinical processes

7. Please describe how lean implementation has helped you to understand

8. Key performance indicators and overall CQMHAODS strategy

9. Any other comments

\section{Appendix C: Pre-Lean Findings}

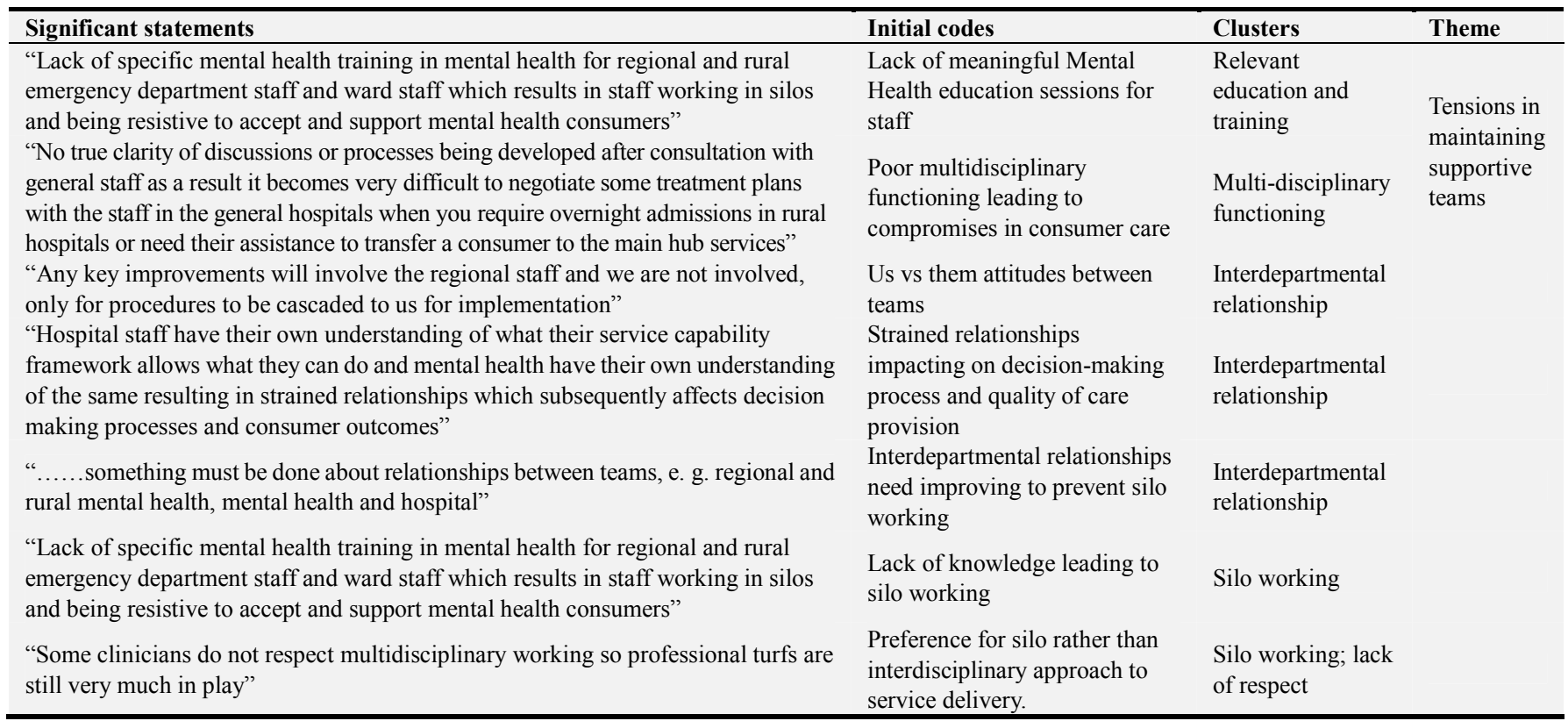

\section{Appendix D: Post-Lean Intervention Findings}

\begin{tabular}{|c|c|c|c|}
\hline Significant Statements & Initial Codes & Clusters & Themes \\
\hline "Lean has helped collaboration between external and internal & Effective collaboration between & Effective & Theme 1: \\
\hline $\begin{array}{l}\text { "Lean initiatives have made work to be more time efficient and } \\
\text { collaborative" }\end{array}$ & $\begin{array}{l}\text { Effective collaboration between } \\
\text { departments }\end{array}$ & $\begin{array}{l}\text { Effective } \\
\text { collaboration }\end{array}$ & $\begin{array}{l}\text { working between } \\
\text { departments to improve }\end{array}$ \\
\hline $\begin{array}{l}\text { "Provided a good opportunity to sit down with colleagues and } \\
\text { look at current processes and working towards improvement" }\end{array}$ & $\begin{array}{l}\text { Networking and building } \\
\text { relationships }\end{array}$ & $\begin{array}{l}\text { Effective networking } \\
\text { and relationship } \\
\text { building }\end{array}$ & $\begin{array}{l}\text { processes, relationship } \\
\text { building and consumer } \\
\text { outcomes }\end{array}$ \\
\hline "Has helped us to work as a team" & $\begin{array}{l}\text { Networking and building } \\
\text { relationships }\end{array}$ & $\begin{array}{l}\text { Effective networking } \\
\text { and relationship } \\
\text { building }\end{array}$ & \\
\hline $\begin{array}{l}\text { "With more consistent processes implemented and having had the } \\
\text { team decisions where everyone takes ownership, if there has been } \\
\text { problems, staff are able to discuss as a team and come up with } \\
\text { solutions that are sustainable and separate the processes that's not } \\
\text { needed" }\end{array}$ & $\begin{array}{l}\text { Networking and building } \\
\text { relationships }\end{array}$ & $\begin{array}{l}\text { Effective networking } \\
\text { and relationship } \\
\text { building }\end{array}$ & \\
\hline $\begin{array}{l}\text { "The workshops have been of great benefit in getting all parties } \\
\text { involved in care provision to get together, fine tune processes and } \\
\text { implement them together" }\end{array}$ & $\begin{array}{l}\text { Involvement of staff from } \\
\text { different departments to develop } \\
\text { process }\end{array}$ & $\begin{array}{l}\text { Staff involvement in } \\
\text { developing processes }\end{array}$ & \\
\hline $\begin{array}{l}\text { "I was sceptical at first, however, Lean enabled good discussions } \\
\text { which encouraged different clinicians to be involved" }\end{array}$ & $\begin{array}{l}\text { Involvement of staff from } \\
\text { different departments to develop } \\
\text { process }\end{array}$ & $\begin{array}{l}\text { Staff involvement in } \\
\text { developing processes }\end{array}$ & \\
\hline "Initial discussions were held to identify problems, and activities & Involvement of staff from & Staff involvement in & \\
\hline
\end{tabular}




\begin{tabular}{|c|c|c|c|}
\hline Significant Statements & Initial Codes & Clusters & Themes \\
\hline $\begin{array}{l}\text { were carried out to develop new standard practices by all the } \\
\text { staff" }\end{array}$ & $\begin{array}{l}\text { different departments to develop } \\
\text { process }\end{array}$ & developing processes & \\
\hline $\begin{array}{l}\text { "Kaizen Workshop gave an insight into other service areas } \\
\text { demand and issues" }\end{array}$ & $\begin{array}{l}\text { Acquired insight and } \\
\text { understanding of the service needs } \\
\text { of other departments }\end{array}$ & $\begin{array}{l}\text { Enhancing corporate } \\
\text { knowledge }\end{array}$ & \\
\hline $\begin{array}{l}\text { "Coming from different clinical practice, I was able to quickly } \\
\text { grasp the processes" }\end{array}$ & $\begin{array}{l}\text { Acquired insight and } \\
\text { understanding of the service needs } \\
\text { of other departments }\end{array}$ & $\begin{array}{l}\text { Enhancing corporate } \\
\text { knowledge }\end{array}$ & \\
\hline $\begin{array}{l}\text { "Enabled me to fully understand the rural mental health pathways } \\
\text { and the issues encountered by staff and consumers on daily basis" }\end{array}$ & $\begin{array}{l}\text { Acquired insight and } \\
\text { understanding of the service needs } \\
\text { of other departments }\end{array}$ & $\begin{array}{l}\text { Enhancing corporate } \\
\text { knowledge }\end{array}$ & \\
\hline $\begin{array}{l}\text { "I do look forward to using the Lean process more in further } \\
\text { change and activities in this workplace. I found even from the one } \\
\text { workshop it was empowering and increase work satisfaction." }\end{array}$ & $\begin{array}{l}\text { Empowering staff increasing staff } \\
\text { satisfaction }\end{array}$ & Empowerment of staff & \\
\hline $\begin{array}{l}\text { "Lean initiatives have provided a way to have visible participation } \\
\text { and sharing ideas to include staff in the decision making process" }\end{array}$ & $\begin{array}{l}\text { Empower staff participation and } \\
\text { sharing of ideas }\end{array}$ & Empowerment of staff & \\
\hline $\begin{array}{l}\text { "The rural mental health team have made suggestions to improve } \\
\text { their workplace and have made a number of significant } \\
\text { improvements for our consumers" }\end{array}$ & $\begin{array}{l}\text { Staff empowerment in workplace } \\
\text { improvements }\end{array}$ & Empowerment of staff & \multirow{6}{*}{$\begin{array}{l}\text { Theme } 2 \text { : } \\
\text { Increased } \\
\text { accountability for } \\
\text { clinicians to adhere to } \\
\text { standard procedures } \\
\text { and improve the quality } \\
\text { of care provided }\end{array}$} \\
\hline $\begin{array}{l}\text { "All clinicians are now accountable for the work they do or not } \\
\text { have done. It also reminds clinicians of work they have not yet } \\
\text { completed and are able to track their cases" }\end{array}$ & Increasing accountability of staff & $\begin{array}{l}\text { Improved } \\
\text { accountability }\end{array}$ & \\
\hline "It makes clinicians to be more accountable" & Increasing accountability of staff & $\begin{array}{l}\text { Improved } \\
\text { accountability }\end{array}$ & \\
\hline $\begin{array}{l}\text { "The positive outcome of introducing the Lean initiatives is it has } \\
\text { made clinicians to be more accountable, streamline admission and } \\
\text { transfer processes and to give a structure/framework to the work } \\
\text { we do in mental health." }\end{array}$ & Increasing accountability of staff & $\begin{array}{l}\text { Improved } \\
\text { accountability }\end{array}$ & \\
\hline $\begin{array}{l}\text { "developing standard work and clear processes through Kaizen } \\
\text { workshops gave clarity on expectations and resulted in consistency" }\end{array}$ & $\begin{array}{l}\text { Enhanced clarity of expectations } \\
\text { and responsibilities }\end{array}$ & $\begin{array}{l}\text { Clear responsibilities } \\
\text { and expectations }\end{array}$ & \\
\hline $\begin{array}{l}\text { "Clinicians now have a better understanding of their } \\
\text { responsibilities" }\end{array}$ & $\begin{array}{l}\text { Enhanced clarity of expectations } \\
\text { and responsibilities }\end{array}$ & $\begin{array}{l}\text { Clear responsibilities } \\
\text { and expectations }\end{array}$ & \\
\hline
\end{tabular}

\section{References}

[1] Australian Institute of Health and Welfare (2018). Mental health services in Australia 2007-08. Australian Institute of Health and Welfare, Canberra

[2] Graban, M. (2009). Lean hospitals. New York, NY: Productivity Press.

[3] Liker J. (2004) The Toyota Way - 14 Management Principles from the World's Greatest Manufacturer. New York, NY: McGraw-Hill.

[4] Womack, J. and Jones, D. (2003). Lean Thinking: Banishing waste and create wealth in your corporation. New York: Free Press.

[5] Brandao de Souza, L, \& Pidd, L. (2008). Exploring the barriers to Lean Healthcare Leadership in Health Services, 22 (2), 121-139.

[6] Braun, V. and Clarke, V. (2006) Using thematic analysis in psychology. Qualitative Research in Psychology, 3 (2). pp. 77-101. ISSN1478-0887

[7] Maxwell, J. A. (2008). Designing a qualitative study. In D. J. Rog \& L. Bickman (Eds.), The handbook of applied social research methods ( 2 ed.) Thousand Oaks CA: Sage.
[8] Yin, R. K. (2008). Case study research: Design and methods (4th ed.). Thousand Oaks: Sage Publications.

[9] Tharenou, P, Donohue, R, and Cooper, B. (2007). Management Research Methods. New York: Cambridge University Press

[10] Boyatzis RE (1998) Transforming Qualitative Information. Sage: Cleveland

[11] Taiichi Ohno, (1988) The Toyota Production System - Beyond large scale production, Portland: Productivity Press.

[12] Black J, Miller D. (2008) The Toyota Way to Healthcare Excellence: Increase Efficiency and Improve Quality with Lean. Chicago, IL: Health Administration Press; 2008.

[13] Graban M. (2012) Lean hospitals: Improving quality, patient safety, and employee engagement. 2nd. New York: Productivity Press/Taylor \& Francis; 2012

[14] Martin, B. O, Kolomitro, K, \& Lam, T. (2014). Training methods: A review and analysis. Human Resource Development Review, 13, 11-15.

[15] Hummel, J. J. (2016). Impact of a process improvement program on healthcare staff: A qualitative case study (Doctoral dissertation). Available from Proquest Dissertations and Theses. 